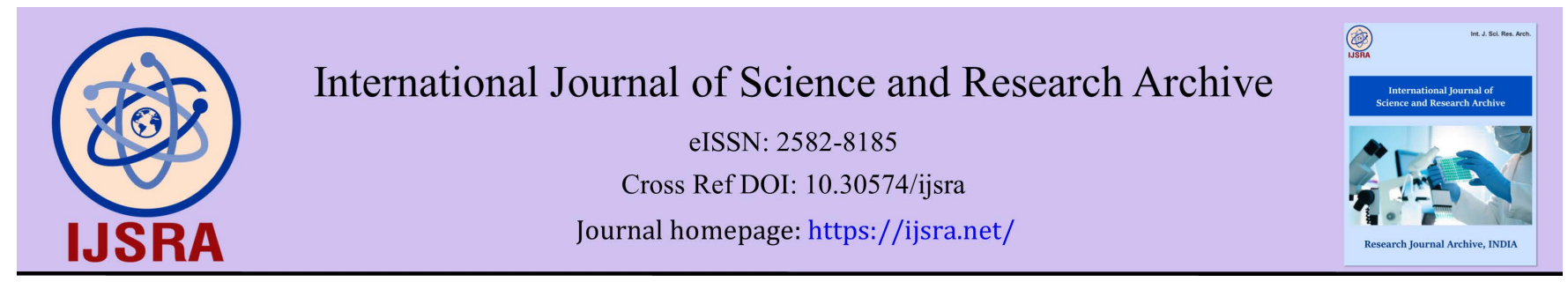

(REview ARTicle)

\title{
Genetic improvement of the dairy cattle in the tropical countries: A review
}

\author{
Firas R Al-Samarai ${ }^{1,}{ }^{*}$, Tamara N Dawood ${ }^{1}$, Oday K Luaibi ${ }^{2}$ and Ahmed M Al-Nedawi ${ }^{3}$ \\ ${ }^{1}$ Department of Veterinary Public Health/College of Veterinary Medicine/University of Baghdad/Iraq. \\ ${ }^{2}$ Department of Internal Medicine and Preventive/College of Veterinary Medicine/University of Baghdad/Iraq. \\ ${ }^{3}$ Department of Animal Production/College of Agricultural Engineering Sciences/University of Baghdad/Iraq.
}

International Journal of Science and Research Archive, 2021, 03(02), 188-192

Publication history: Received on 17 September 2021; revised on 19 October 2021; accepted on 21 October 2021

Article DOI: https://doi.org/10.30574/ijsra.2021.3.2.0138

\begin{abstract}
The principles of genetic improvement included the use of crossbreeding. An alternative method is the genetic improvement of the indigenous cattle by selection.

The low reproductive performance and high calf mortality in the indigenous cattle caused a reduction in the selection intensity. Moreover, the generation interval is long in cattle because of the late sexual maturity and the long calving intervals. The most important problem is the absence of a milk recording system in many temperate countries. In such a case, the approach to improving the cattle through selection is limited and we will need to start with a single nucleus.

Two types of selection can be adopted; without progeny testing which means the selection of bulls on pedigree information only and with progeny testing to identify the elite bulls according to the performance of their daughters.
\end{abstract}

Keywords: Progeny test; Selection; Dairy cattle; Tropical countries

\section{Introduction}

The zebu (Bos indicus) type included most tropical cattle. These cattle are characterized as are well adapted to the harsh environmental conditions in the tropics. After hundreds of generations under the tropical condition, natural selection provided them more tolerance to heat stress, resistance to many tropical diseases, and the ability to survive under the feed and water shortage. On the other hand, the genetic potential is poor for both productive and reproductive performance, such as low milk yields, late maturing, high calf mortality, long calving intervals, a high number of insemination per conception, and low fertility.

The strategies that were used to improve the dairy performance of tropical cattle represented by imported the dairy breeds of the European (Bos Taurus) type, either as a stock of both sexes in large numbers or by acquiring bulls (or semen) for crossbreeding with indigenous females. Both approaches have been applied, and the results have been different. Imported temperate breeds can be successful in countries with moderate heat stress, good feeding, high management, and available veterinary services (Berglund, 2008). All these factors represent the most challenges faced by breeders in tropical countries. However the crossbreeding led to a dramatic increase in productivity in the first crossbred generation $(\mathrm{Fl})$, but the continuous upgrading by repeated backcrossing to exotic bulls lead to a lack of adaptation (Syrstad, 1996). After the first crossbreeding, the performance of the second-generation will deteriorate due to the reduction in heterosis (hybrid vigour) expected from Fl to subsequent generations (retained heterosis).

\footnotetext{
${ }^{*}$ Corresponding author: Firas R Al-Samarai

Department of Veterinary Public Health/College of Veterinary Medicine/University of Baghdad/Iraq.

Copyright $(2021$ Author(s) retain the copyright of this article. This article is published under the terms of the Creative Commons Attribution Liscense 4.0.
} 
The genetic resources of tropical cattle will be subject to reduction as a result of the increase of genetic material of imported cattle (Scholtz et al., 2008). The loss of indigenous genetic properties of the cattle which are essential for survival and reproduction in the tropics is considered an irreplaceable loss. It is important to preserve these for future use. Hence it was proposed that any cattle development project should include a statement about repeated crossing and it's possible to decrease the local genetic resources that should be maintained (Munywoki, 2021). However, artificial selection is a good tool for genetic improvement as an alternative method to genetic material importation. The application of selection is too limited in tropical countries. The results obtained by selection in many temperate breeds suggest that there should be a good chance for improving the dairy performance of tropical cattle by the same method particularly there is a high genetic variation among individuals. Therefore, the purpose of the present article is to explore the prospects of applying the selection for improvement the cattle performance.

Aspects of selection in tropical cattle

The genetic change in the population means in one generation brought about by selection, is determined by:

\section{$\Delta \mathrm{G}=$ The genetic change (Response)}

$\mathrm{i}=$ is the intensity of selection which is determined by the proportion selected, and can be found from tables in most textbooks on animal breeding (Falconer and Mackay, 1996).

$\mathrm{H}^{2}=$ the heritability of the trait

$\sigma$, which is the selection differential (i.e. the superiority of the individuals selected for breeding, above the means of the population prior to selection), in units of phenotypic standard deviation.

If any of these three parts is low, genetic progress through selection will be slow.

\section{Genetic variability}

The standard deviation of milk yield in tropical cattle is less than in temperate dairy breeds. But, relative to the mean, the variability is usually greater in tropical than in temperate cattle.

Many estimates of standard deviations of milk yield in tropical cattle obtained by several studies are biased because records for short lactations were deleted. Mchau (1988) estimated the mean and the phenotypic standard deviation of lactation yield in a herd of Mpwapwa cows (crossbreed) at 1072 and $775 \mathrm{~kg}$ respectively. He found that about $40 \%$ of the lactations were shorter than 200 days. When these were excluded, the mean increased to $1539 \mathrm{~kg}$, but the standard deviation decreased to $572 \mathrm{~kg}$. The high proportion of short lactations in this and other tropical breeds could be attributed to the milk let-down problem when the cows are milked in absence of the calf. Lactation length is a heritable trait and closely correlated with lactation yield. Rege et al. (1992) studied the records of a Sahiwal herd in Kenya and reported that the mean lactation yield was $1145 \mathrm{~kg}$ for first lactations and $1663 \mathrm{~kg}$ for all lactations combined, with standard deviations of 523 and $572 \mathrm{~kg}$ respectively. This gives coefficients of variation (CV) is more than twice those commonly observed in temperate dairy breeds.

\subsection{Intensity of selection}

The proportion of individuals is needed for breeding in order to maintain herd size determined by the reproductive rate of the species. The reproductive rate is low in cattle, particularly for the females, and lower in tropical than in temperate breeds (. In zebu herds the calving rate is rarely above $80 \%$ and sometimes as low as $50 \%$. In addition, the mortality of calves in early and advanced age is often high. The average number of progeny reaching breeding age out of each female in her lifetime is an important parameter(Al-Samarai and Al-Zaydi, 2014).

\subsection{Accuracy of selection}

When selection is based on the phenotype of the individual, the accuracy equals the square root of the heritability ( $\left.\mathrm{h}^{2}\right)$. The heritability of milk yield in tropical cattle is not accurate because of many reasons such as a low number of records and the absence of a recording system, but most estimates reported fall within the same range as those obtained in temperate breeds (0.15 to 0.4)(Al-Samarai et al., 2015). Heritability of the 305-day milk yield of Sahiwal was $0.082 \pm$ 0.07 in Pakistan and the breeding values of sires and cows ranged from -293 to 506 and -278 to $512 \mathrm{~kg}$, 
respectively(Khan et al., 2008). Singh et al., (2017) analyzed a total of 2985 records on lactation yield of Sahiwal cattle over a period of 62 years (1949 to 2011) and found that the heritability for total milk production was $0.105 \pm 0.035$ and breeding values of sires ranged from -121.38 to $103.69 \mathrm{~kg}$.

\subsection{Selection after breeding}

The complicated problem in dairy cattle breeding is that milk yield cannot be recorded unless the heifers have been used for breeding. When the first lactation record of females is completed, most of the cows are into their second pregnancy; therefore, the selection of cows on the basis of their first lactation will affect only calves born in third and subsequent parties. The selection differential arises because the better performing cows are allowed to produce more calves than the poorer. This selection could be adopted by culling calves and heifers depending on their ancestors' performance.

\subsection{Selection for sex-limited traits}

The traits in dairy cattle are expressed only by females; therefore, the selection of bulls must be based on the performance of their female relatives (dam, half-sisters, and daughters). Selection on the basis of the dam can be applied at birth, but unfortunately, it has low accuracy. Maternal half-sisters have a few records and are not offered much information at this stage, while the paternal half-sisters (daughters of the calf's sire) could be many. The progeny test of sires depend on their daughters offered accurate information but need about 5-6 years after the bull has been first used for breeding.

Reliable progeny testing requires that the daughters of the various bulls should be reared under similar conditions. In practice, this is difficult to achieve when there are several herds but it can accomplish if the bulls have been used in the same herd(s), or their daughters are distributed at random across many herds when using artificial insemination. Several factors should exist to achieve efficient use of progeny testing such as a large breeding unit, a modern data analysis, a large recording system, and good organization.

\section{Generation interval}

The genetic response (R) might be more informative if it was dividing by the generation interval. The generation interval is defined as the average age of the parents when their progenies are born. It was longer in cattle than in most other livestock species, and longer in tropical than in temperate cattle because tropical cattle reach sexual maturity at a higher age and also have longer calving intervals. If the cows are on average 3 years old at first calving and calve five times at intervals of 1.5 years, the generation interval from dams to their progenies will be 6 years. Further, if bulls start breeding at 2 years of age and are used consecutively for the next 2 years, this gives a generation interval of slightly less than 4 years. With extensive use of progeny testing the generation interval from sires to their progenies increases to 7-8 years or more.

\subsection{Strategies for genetic improvement in a closed herd}

The extensive milk recording schemes which form the basis of dairy cattle breeding programs in many temperate countries do not exist in the tropics, and cannot easily be established. In addition, artificial insemination often does not function properly (Gamborg, and Sandoe, 2005). It might therefore be preferable to start a genetic improvement program with a single herd (or a group of cooperating herds).

\section{Conclusion}

In the absence of $\mathrm{AI}$ and semen storage facilities, there is a risk represented by the fact that the bulls have to be kept alive until their daughters have finished the first lactation to be able to make the progeny test. Moreover, if the program is set up at year 0 , the progeny test could be useful after about 10 years, while when the generation intervals are lower we can achieve the first genetic benefits at an earlier stage and can be disseminated rapidly to the whole population (Ruane and Smith, 1989). The results from the experiment of progeny testing in a herd of Sahiwal cattle in Kenya confirmed that such a program can be inefficient (Rege and Wakhungu, 1992). Furthermore, progeny testing is effective in large herds with hundred cows, while, pedigree selection can be used in smaller herds and the response is mostly independent of herd size.In closed breeding schemes, inbreeding is inevitable in the herd. The rate of inbreeding coefficient depends on the number of males their number is smaller than the number of females (Falconer and Mackay, 1996). Prediction of inbreeding rates is quite complex, especially in populations undergoing selection. Nevertheless, we can predict that inbreeding rates would be higher in the progeny testing scheme because all young bulls are bred by a single male, whereas in the pedigree scheme they can be bred by up to 10 males. The accumulation of inbreeding in the 
nucleus herd should not be a major problem as it can be monitored continuously and animals from outside the herd can be introduced if inbreeding is considered to be too high.

It is essential that the genetic responses, achieved in the nucleus, be disseminated to the whole population. The bulls available for distribution would be young bulls selected on the basis of pedigree. If all bulls with above average pedigree (top 50\%) are considered acceptable, a nucleus herd can provide about 15 bulls per 100 cows in the herd per year. Most of these bulls can be distributed as yearlings, but the most promising ones would be available only after having served in the herd for a year or so. the gain achieved in the nucleus will be disseminated to the outside herds with a genetic lag of about two generations (James, 1977).

\section{Compliance with ethical standards}

\section{Disclosure of conflict of interest}

The authors have no conflict of interest.

\section{References}

[1] Al-Samarai FR, Abdulrahman YK, Mohammed FA, Al-Zaidi FH and N.N. Al-Anbari NN. Comparison of several methods of sires evaluation for total milk yield in a herd of Holstein cows in Yemen. Open Veterinary Journal, (2015), 5(1): 11-17.

[2] Al-Samarai FR, Al-Zayd FH. Genetic evaluation of longevity in dairy cattle. Applied Science Reports.2014,7(1):2531.

[3] Berglund B. Genetic improvement of dairy cow reproductive performance. Reprod Domest Anim. 2008;43 Suppl 2:89-95. doi: 10.1111/j.1439-0531.2008.01147.x. PMID: 18638109.

[4] Cunningham EP, Syrstad O. Crossbreeding Bos Taurus and Bos indicus cattle for milk production in the tropics. Animal Production and Health paper 68, FAO, Rome. 1987.

[5] Falconer DS, Mackay TFC. Introduction to Quantitative Genetics, (Longman Group Uk Ltd, Harlow). 1996.

[6] Gamborg, C. Sandoe, P. Sustainability in farm animal breeding. A review. Livestock Production Sci. 2005; 92: 221231.

[7] Hall SJG, Ruane J. Livestock breeds and their conservation - a global overview. Conservation Biology. 1993; 7 : 815-825.

[8] Hall SJG. Conservation of livestock breeds. Proceedings of Workshop on African Animal Genetic Resources: Their Characterization, Conservation and Utilization, ILCA, Addis Ababa, 19-2l February. 1992; 1l-16.

[9] James J. Open nucleus breeding systems. Animal Production. 1977; 24: 287-305.

[10] Khan MS, Bilal G, Bajwa IR, Rehman Z, Ahmad S. Estimation of breeding values of Sahiwal cattle using test day milk yields. Pakistan Vet. J. 2008; 28(3): 131-135.

[11] Mchau kW. Production characteristics of Mpwapwa cattle. I. Lactation length and yield. World Animal Review. 1988; 55: 11-17.

[12] Munywoki G. N. Adapting To the Effects of Climate Change on Livestock Production through Animal-Breeding in Kenya: A Brief Review of the Literature. Medicine: Int J Vet Sci Med Diagn 2021, 2: 2:1-4.

[13] Rege JEO, Wakhungu JW. An evaluation of a long-term breeding programme in a closed Sahiwal herd. II. Genetic and phenotypic trends and levels of inbreeding. Journal of Animal Breeding and Genetics. 1992; 169: 374-384.

[14] Rege JEO, Lomole MA, Wakhungu JW. An evaluation of a long-term breeding programme in a closed Sahiwal herd. I. ERect of non-genetic factors on performance and genetic parameter estimates. Journal of Animal Breeding and Genetics. 1992; 169: 364-373.

[15] Robertson A. Optimum group size in progeny testing and family selection. Biometrics', 13, 442-450 Roberston, A. and Rendel, J.M., 1950. the use of progeny testing with artificial insemination in dairy cattle. Journal of Genetics. 1957; 56: 2l-3l. 
[16] Ruane J, Smith C. The genetic response possible in dairy cattle improvement by setting up a multiple ovulation and embryo transfer (MOET) nucleus scheme. Genetics, Selection and Krolution. 21: 169-183.

[17] Scholtz MM, Bester J, Mamabolo JM, Ramsay KA. Results of the national cattle survey undertaken in South Africa, with emphasis on beef. Appl Anim Husb Rural Dev 2008;1:1-9.

[18] Singh J, Singh VK, Yadav AK, Jha AK. Effect of genetic and non-genetic factors on lactation yield in Sahiwal cattle .Indian J Anim Res. 2017; (51): 570-575.

[19] Syrstad O. Erect of intensive culling in dairy herds. Acta Agriculturae Scandinavica. 1972; 22: 25-28.

[20] Syrstad 0. Dairy cattle crossbreeding in the tropics: Choice of crossbreeding strategy. Trop. Anim. Health and Prod. 28 (1996), 223-229

[21] Vaccaro LP de. Some aspects of the performance of purebred and cross-bred dairy cattle in the tropics. Part 1. Reproductive efficiency in females. Animal Breeding Abstracts. 1973; 41: 571-59l.

[22] Vaccaro LP de. Some aspects of the performance of European purebred and cross-bred dairy cattle in the tropics. Part 2. Mortality and culling rates. Animal Breeding Abstracts. 1974; 42: 93-102. 